\title{
Anti-EGFR Monoclonal Antibody GT-MAB 5.2-GEX
}

National Cancer Institute

\section{Source}

National Cancer Institute. Anti-EGFR Monoclonal Antibody GT-MAB 5.2-GEX. NCI

Thesaurus. Code C94221.

A glycoengineered form of a human monoclonal antibody directed against the epidermal growth factor receptor (EGFR) with potential antineoplastic activity. Anti-EGFR monoclonal antibody GT-MAB 5.2-GEX specifically binds to the extracellular domain of EGFR, thereby potentially inducing an antibody-dependent cell-mediated cytotoxicity (ADCC) against EGFR-expressing tumor cells, eventually leading to tumor cell apoptosis and an inhibition of tumor cell growth. EGFR, a member of the epidermal growth factor family of extracellular protein ligands, is overexpressed on the cell surfaces of various solid tumors. This antibody has a specific glycosylation profile that may enhance its ADCC response against EGFR-expressing tumor cells. 